\title{
The Tomb of Penamun at Deir El-Madina
}

\section{TT213}

Hebatallah Sobhy Ibrahim Abdou

Faculty of Tourism and Hotel Management- Sadat City University.

\begin{abstract}
The tomb of Penamun TT213 is located at Deir El-Madina, it consists of an undecorated chapel, in which the entrance doorway has a surviving scene and a text dedicated to Penamun, who holds the title "Servant in the Place of Truth". He is shown in the tomb together with his family. Bruyère in his description of the tomb, related the opposite shaft with a burial chamber to Penamun, and considered them part of his burial place. This will be discussed in details, as well as the affiliation of Penamun. The discussion will be based on the source evidence from the tomb itself and the other monuments related to the same person, in which he appeared together with his family. The source evidences will be transliterated, translated and discussed in details in theresearch.
\end{abstract}

\section{The tomb}

The tomb of Penamun TT213, at Deir El-Madina, shares a courtyard with the tomb of Amenmes TT9, to the south of the tomb of Ken TT4.' Bruyère ${ }^{r}$ described the tomb as a small undecorated chapel, with only the entrance doorway engraved to show the owner of the tomb as the Servant in the Place of Truth Penamun. A set of stairs also leads from the courtyard to a burial chamber.

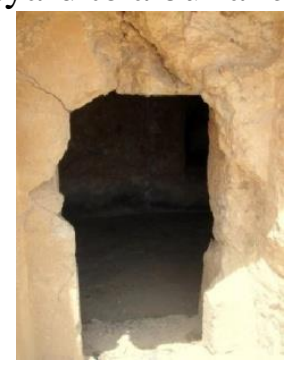

Fig. 1- The Entrance doorway of the tomb. of the tomb (after

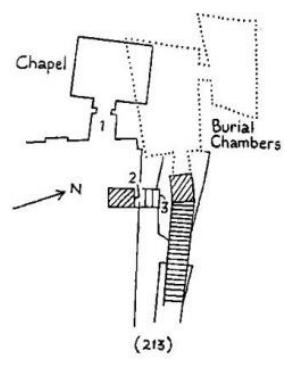

Fig. 2- Plan

PM I: 1, p. 308).

\footnotetext{
'PM I: 1, p.310; Černý, Répertoire, p. 93; Bruyère, Rapport (1924- 25), p. 183-188.

'Bruyère, Rapport (1924- 25), p. 183.
} 
The text around the entrance doorway of the chapel is still visible, although the upper lintel is damaged apart from a faded scene of the deceased and his family. Facing the doorway, the left side shows some cracks and partial damage near its middle, affecting the text of the first and second columns. On the right side, the upper parts of the texts of all columns are now lost. The reveals of the doorway are also lost, with no traces of text. The doorway together with the inscribed area around it is $1.18 \mathrm{~m}$ wide and $1.95 \mathrm{~m}$ height. The thickness of the doorway is $0.25 \mathrm{~m}$.

Inside the chapel, the entrance wall is $3.9 \mathrm{~m}$ in width. The measurements of the hall are: the right and left walls each $2.5 \mathrm{~m}$ long, and the back wall $3.15 \mathrm{~m}$, with a niche $0.25 \mathrm{~m}$ from the left side facing out. This niche is $0.55 \mathrm{~m}$ above the ground level and $0.85 \mathrm{~m}$ in depth. The height of the hall is $1.95 \mathrm{~m}$. In the courtyard, the access to the burial chamber is now blocked. The shaft with stairs is now filled in, and the only sources for the scenes and texts of the entrance of the burial chamber are the copies of Bruyère $^{r}$ andČerný. ${ }^{\ddagger}$

The fragmentary scene and text of the entrance doorway of the chapel as presented by Bruyère, show more than is now visible in the tomb itself. It consists of a fragmentary scene on the upper part of the entrance door, with four vertical lines of text on each side of the entrance. The right side already suffers from severe damage, as well as the right upper part of the entrance lintel. The reveals of the door jambs are also inscribed with a single vertical column of text on each side. The decoration of the tomb is in the monochrome style which identified by Bruyère as belonging to the $19^{\text {th }}$ dynasty. ${ }^{\circ}$ The published text is a hand copy, and not completely accurate epigraphically.

\footnotetext{
" Bruyère, Rapport (1924-25), p. 183-188.

¿ Černý, Répertoire, p. 93; KRI III: 730:13, 731:b, c.

• Bruyère, Tombes á decoration monochrome, p. 88-97; Lee \& Quirke, Pigments, p.107-118; Lucas, Ancient Egyptian Materials, p.338-356.
} 


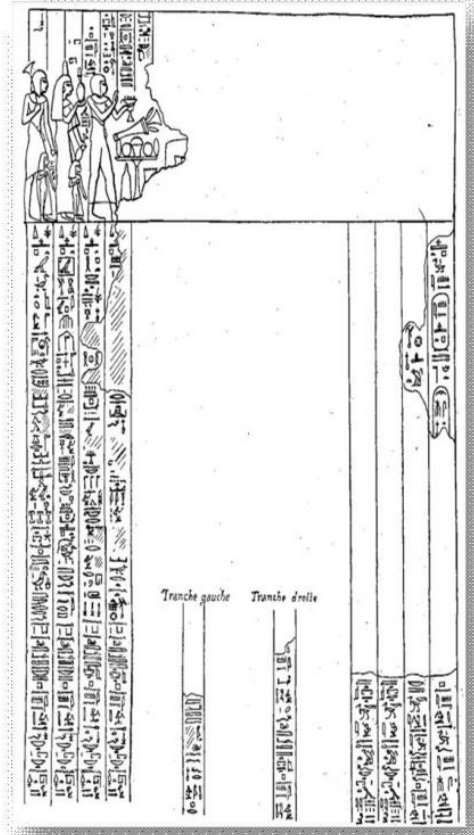

Fig. 3- layout of the entrance doorway of the tomb of Penamun TT213. (after Bruyère, Rapport (1924- 25), p. 183).

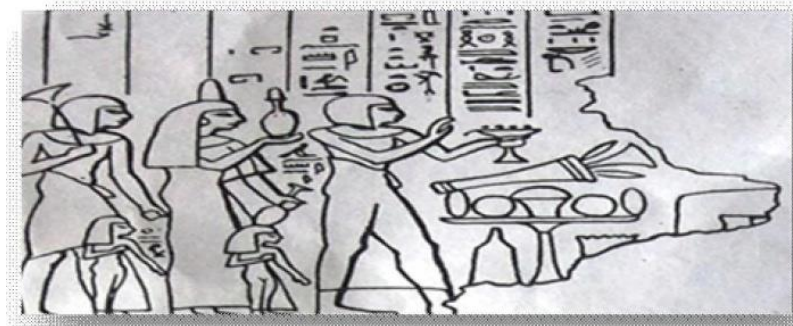

Fig. 4-The upper lintel of the entrance doorway (after. Bruyère, Rapport (1924- 25), p. 183).

The fragmentary scene depicts the tomb owner Penamun together with his wife, another male figure, and two female children, in front of a heaped offering table, with traces of a seated deity. Penamun is standing. He is holding an incense burner in his left hand, with his right arm in a gesture of adoration. He is wearing a wig, wide collar, and a long kilt. The text above his head identifies himas:

[......t.t pn-imn mAa xrw. Penamun, True of voice.

Behind Penamun his wife is carrying a jar in her left hand, and presenting a sacred jar on the palm of her right hand. She is wearing a long 


\section{The Tomb of Penamun at Deir El-Madina}

TT213

Dress, and long wig surrounded with an incense cone. Traces of her name can still be seen in the text above head.

[nbt]pr[nbt-n]h[t]. [Lady of the] House,[Nebt-ne]h[et].

Next to the wife stands a small scale figure of a female child, who is shown with transparent long dress, with long wig. The child's right arm is resting on her heart. There is a text above her head, between the hands of Nebetnehet, which seems too distant to be her name, and may rather belong to the offering ceremony:

m(i)(?) n(.i) Imn "Come to me (?) Amen(?)."

There is room in front of her face for a name, but Bruyère's copy does not show one, and none is now visible. Behind Penamun's wife stands a male figure with his left leg forward. He is holding a papyrus plant in his right hand, which is raised to his heart. His left hand is empty. He is wearing a wig, wide collar, and a short kilt, with his tummy bulging out above the kilt. Traces of a hieroglyphic inscription above his head read: [......sn.f]

[....his brother ....], but the name is lost. A second small girl, depicted in the same way as the first, stands beside him, Bruyère's copy shows an unreadable name in front of her face, but the copy is clearly inaccurate here: the photograph shows the inscriptions higher up behind the man's arm. The traces might possibly represent a name Ast "Isis", but the reading is very uncertain.

The rest of the upper lintel scene is damaged, It may originally have contained a double scene of seated gods, with Penamun and his family on the left side, and Baki (Penamun's father), and his family to the right side. This reconstruction is based on the doorway texts, where the left side is dedicated to Penamun and his family, and the right side to Baki and his family. The text of the upper lintel reads:

Dd xt nb [nfr] wab [n] nbw r nHH m-Drt sDm-aS m st mAat Hr imntt wAst......t pn-imnmAa xrw [snt.f nbt] pr [nbt-n]h[t] [mAa-xrw] [....] sn.f $[\ldots]$

Giving all [good] and pure things [to] the Lords of Eternity by the hand of the Servant in the Place of Truth on the West of Thebes, the [. ] Penamun true of voice. [His sister Lady of the] House, [Nebet-ne]h[et] [true of voice $][\ldots \ldots . . . .$.$] hisbrother [\ldots \ldots \ldots \ldots . . .$.$] .$

Each side of the doorway is inscribed with four vertical lines of hieroglyphs. The left side survives apart from partial damage in the first and second columns.

`PM I: 1, p.310; Černý, Répertoire, p. 93; KRI III: 730:13, 731:1-4, Bruyère, Rapport (192425), p. 183-188. 


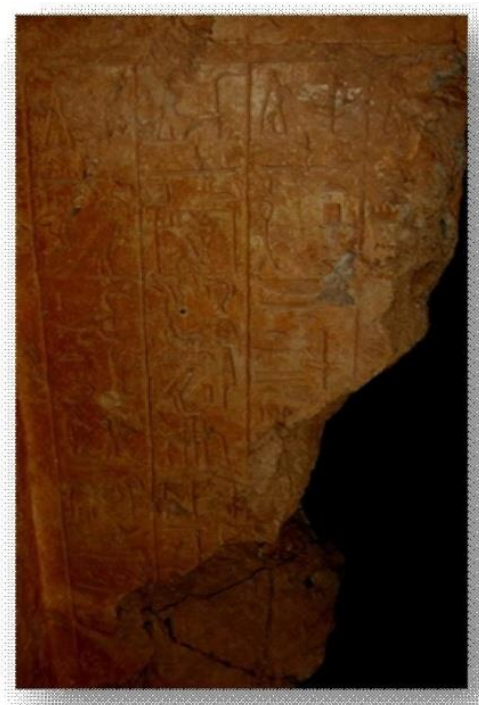

Fig.5- The upper part of theleftjamb.

of the leftjamb.

The first column reads:

$\mathrm{H}[\mathrm{t}] \mathrm{p}$ [di] nsw [imn-ra..... q]rst nfr [ $. \operatorname{im}] \mathrm{nt}(?) \mathrm{Hsy}[\ldots \ldots \ldots \ldots \ldots \ldots \ldots \ldots \ldots \ldots . .$. wrt nt wAst n kA n sDm aS m st mAat pn-imn mAa xrw snt.f nbt pr nbt-nht mAa xrw

An offering the king gives (and) Amen-Re...... good [bu]rial [on the [we]st, favours, ...... great $[\ldots ? . .$.$] of Thebes to the ka of the Servant in the Place of$ truth Penamun, true of voice. His wife Lady of the house Nebetnehet, True of voice.

The second column reads:

Htp di nsw PtH nb mAat nsw tAwy nfr $\mathrm{Hr}$ [nb] nHH [Dt] Ssp snw [Hr] wDHw n nb nTrw Sms.i sqr [...] hrw pXr inbw n kA n sDm aS m st mAat pn-imn mAa Hrw snt.f nbt pr nbt-nht mAa xrw

An offering the king gives (and) Ptah Lord of Justice, King of the Two Lands, Beautiful of Face [Lord of] Eternity [forever], receiving loaves [on] the offering table of Lord of the Gods, so I may follow Sokar [....] on the day of going round the walls, to the ka of the Servant in the Place of Truth Penamun, true of voice. His sister? Lady of the house Nebetnehet, true of voice.

The third column reads:

Htp di nsw Ht-Hr Ht tp wAst Inpw xnty sH-nTr nTr aA imy wt di.sn rn[p].i(?) $m$ iri.i Hr imn m Hb.f nb Hr Ssp Htp DfAw m Hb.f $n$ int n kA n sDm aS m st mAat pn-imn mAa Hrw snt.f nbt pr nbt-nht mAaxrw 


\section{The Tomb of Penamun at Deir El-Madina}

TT213

An offering the king gives (and) Hathor, who is over Thebes and Anubis before the divine booth, great god, who is in the wt, so they cause that I am flourishing as I act on behalf of Amen in every festival of his, receiving offerings and food in his Festival of the Valley, to the ka of the Servant in the Place of Truth Penamun, true of voice. His sister? Lady of the house

Nebetnehet, true of voice.

The fourth column reads:

Htp di nsw Hr sA ist nTr aA HkA psDt wr n mAnw Di.f aq pr Xrt-nTr nn Sna.tw.i Hr sbAw n DAt n xnr.tw bA m mrr.f n kA n sDm aS m st mAat pnimn mAa Hrw snt.f nbt pr nbt-nht mAa xrw

An offering the king gives (and) Horus, son of Isis, the great god, the ruler of the ennead, the great one of Manu, so he causes going in and out of the necropolis, and I shall not be repelled from the gates of the underworld, and (my) $\mathrm{Ba}$ is not restrained, as it desires, to the ka of the Servant in the Place of Truth Penamun, true of voice. His sister? Lady of the house Nebetnehet, true of voice.

The reveal of the door reads:

[sD]m aS m [st] mAat wnn-nfr mAa xrw

[The Serv]ant in [the place] of Truth, Wennenefer, true of voice.

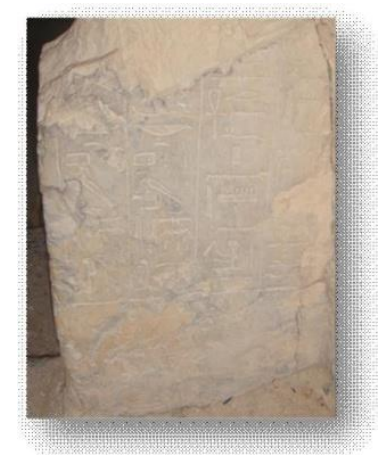

Fig.7- The lower part of the left side of the entrance doorway.

According to Bruyère's copy, traces of the upper part of the first column to the right reads:

... [sDm aS ] m st mAat bAky mAa xrw mwt.f nbt pr tAy-sn mAa xrw ... [the Servant] in the Place of Truth Baky, true of voice. His mother Lady of the House, Taysen, true of voice.

The second column reads:

...[sDm aS ] m st mAat bAky mAa xrw mwt.f nbt pr tAy-sn mAa xrw .. [the Servant] in the Place of Truth Baky, true of voice, His mother Lady of the House, Taysen, true of voice.

The third column reads: 



in sA.f sanx rn.f pn-imn mAa xrw

[...... Thebes Nefer-hotep, and Mut [.......... of the] Lord of the Two

Lands Baky, True of voice. It is his son who makes his name live, Penamun, true of voice.

The fourth column reads:

Htp [di nsw] sA imn imn-Htp mAa xrw HmtnTrIaH-ms-nfrt-[iry

pn-imn mAa xrw sA.f imn-ms mAa xrw

An off[ering] the king gives (and) the son of Amen Amenhotep, true of voice, and the god's WifeAhmose-neferta[ry........... ]Penamun, true ofvoice.

His son Amenmes, true of voice.

The reveal of the door reads:

[......]imn-nxt mAa xrw sA.f sDm aS m st mAat pn-imn mAa xrw

[.....] Amenekhet, true of voice. His son, Servant in the Place of Truth,

Penamun, true of voice.

\section{Comments on the translation of the text:}

Bruyère's copy of the text has some signs which were drawn inaccurately, but by collating pictures of the current state of the text, the following emendments can be made:

- The right side of the entrance doorway, the second column, the words Sms.i sqr is followed by the boat of Sokar, which is not reproduced in Bruyère's copy. The following sign looks like another boat, but the reading remains uncertain.

- The right side of the entrance doorway, the third column, in the words Hb.f $n$ int Festival of the Valley, the " $t$ " is clear, where Bruyère's copy shows an"r".

- The right side of the entrance doorway, the fourth column, the three signs writing the word for the gates of the underworld, should be read as the wall sign (Gardiner O36). After DAt "underworld" the reading should be $n$ xnr.tw. --After the " $n$ " there is no " $r$ ", but only the "baking instrument?" determinative (Gardiner U31), and the "w" of tw is alreadyvisible.

\section{The entrance of the burial chamber:}

The shaft of the burial chamber is now filled in and not accessible. Bruyère described it as stairs leading to a vestibule and two chambers. All of them are undecorated. ${ }^{\vee}$ According to Bruyère, ${ }^{\wedge}$ and Černý, ${ }^{q}$ the lintels and the

\footnotetext{
${ }^{\top}$ Bruyère, Rapport (1924-25), p. 186-7.

${ }^{\wedge}$ Bruyère, Rapport (1924-25), p. 183-188.

` Černý, Répertoire, p. 93.
} 


\section{The Tomb of Penamun at Deir El-Madina}

TT213

twointodividedislintelupperTheinscribed.wereentranceitsoftympanummiddle:

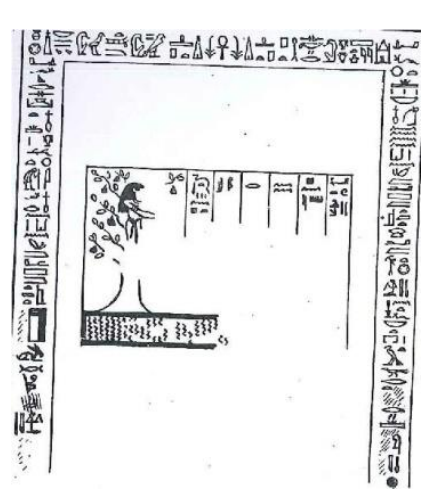

theinsignlifethewithparts,

Fig. 8-The entrance doorway and the tympanum of the burial chamber.

The text of the right side facing reads:

Htp di nsw ptH sqr Hr-ib Sti di.f xt nb nfr wab n kA n sDm aS m st mAat xam-wAst mAa xrw snt.f nbt pr tA-wrt-hr-ti mAa xrw.......[wAs]t.....

An offering the king gives (and) Ptah-Sokar who is in Shetjet-shrine. May he give every pure thing to the ka of the Servant in the Place of Truth Khaemwaset, true of voice. His sister?, Lady of the House, Taweretherti, true of voice...... [Thebe]s.....

The text of the left side facing reads:

Htp di nsw Hr-Axty tmw nb tAwy iwnw di.f qrst nfrt Hr-xt iAw nfr n kA n sDm aS m [st mAat] wnn-nfr mAaxrw. .[i]mn-nxtw

An offering the king gives (and) Horakhty, Atum, Lord of the Two Lands of Heliopolis,. May he give him a good burial after good old age, to the ka of the Servant of the [Place of Truth] Wennenefer, true of voice........ [A]mennekhet. After passing the doorway, you face the tympanum. It shows a scene of Nut as a sycamore tree goddess standing on a pond, with seven column of text in front of her face. The surviving text reads: Ddmdw(i)nNut $[\ldots . . . ..] \operatorname{stmAat}[\ldots ..] \mathrm{r}[\ldots ..] \mathrm{mw}[\ldots \ldots.] \mathrm{Pn}-\mathrm{imn}[\ldots] \mathrm{nxtw}$ mAa $x r w[\ldots .$.$] Words spoken by Nut,[........$ in $[\ldots . . . .$.$] water[.......]Penamun[... ] Nekhet, true of voice.$

The doorway to the burial chamber has dedications to Wennefer and Khaemwaset. The Tympanum here has a third name, which is damaged, that seems to read Amennakhet. The Pn written before the Imn seems to have been treated by Bruyère " as part of a name Pen-amun-nakhet, which doesnot appear on any of the monuments of the family, clearly rather than connecting it with missing word before it: "this[...]". The inscription does not, therefore, identify the burial place as that of Penamun of TT213, but does seem to connect it to his family.

"'Bruyère, Rapport (1924-25), p. 187. 


\section{The representations of Penamun on stelae and} ostraca. 'Stela J.43564:

It was studied by Bruyère, as one of the stelae found by Baraize at Deir el-Madina, " and republished by Kitchen in KRI. The stela is in the form of a door surmounted by a cornice, and made of painted limestone.

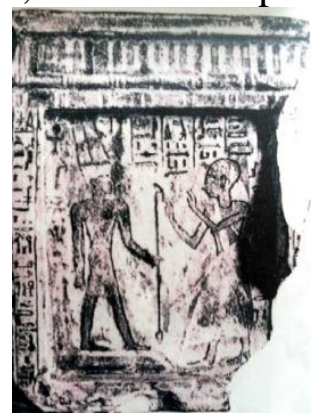

Fig. 9- Stela J.43564 (After Bruyère, ASAE 25(1925), pl. 1(no.1). On the left side facing, the text reads,"

Htp di nsw imn-ra nsw $n$ <nTrw> nb pt HqAwAstdi.f anx wDAsnb $<\mathrm{n}>$ sDm aS $<$ m $>$ st mAat pn-imn

An offering the king gives (and) Amen-Re, the King of the Gods, Lord of the Sky, the Ruler of Thebes: may be give life, prosperity and health, $\langle$ to $>$ the Servant <in> the Place of Truth Penamun.

The right jamb is lost. Inside the frame, there is a representation of Amen standing with his left leg forward, and holding the was sceptre. Amen is wearing a short kilt and a crown with the two plumes above his head. In front of him a textstates:

Imn-ra nb pt nTr aA Amen-Re, Lord of the Sky, the Great God.

Behind him another text, it states:

anx wAs sA HA.f xr nHH Life, prosperity and protection, behind him forever.

In front of him stands an adoring figure, represented with shaven head, wearing a long kilt, sandals and raising his two arms in prayer. Behind him a text states: dwAw n kA.k imn-ra n kA n sDm aS m st mAat xa-m-wAst mAa xrw xr nTr aA Adoration to your ka, Amen-Re; for the ka of the Servant in the Place of Truth, Khaemwaset, true of voice under the great god."

\footnotetext{
"KRI III: 732: 2-6.

"' Bruyère, ASAE 25(1925), p. 80-81, pl. 1(no.1).

"KRI III: 732: 2.

s' Bruyère, ASAE 25(1925), p. 80-81, pl. 1(no.1).
} 
andTT4,KenoftombstheoffrontinfoundwastombKhaemwaset'sofrelativeorcoll eaguecloseaashimidentifiedDaviesTT213.Penamunwifehiswithtogethermentio "nedwasKhaemwasetas

Penamun,theinstairsthebelowchamberburialtheofentrancetheonTawerethertial Penamun.oftombtheofcourtyard" soPenamunandKhaemwaset appeared together on ostracon O.CGC 25341, 3-

4. ${ }^{\vee}$ Stela Cairo Museum J. 72025: ${ }^{\wedge}$

The round topped limestone stela J. 72025 is dedicated to the baboon MoonThot, the lunar deity. The upper register represents a baboon with the moon and sun symbols on his head. He is sitting on a solar boat, which has two papyrus plants at its prows and two steering oars. There are two wadjet eyes at the two sides of the baboon's head, two ears inside the boat, on each side of the baboon; another ear is shown under the boat to the right. The ears all face thegod.

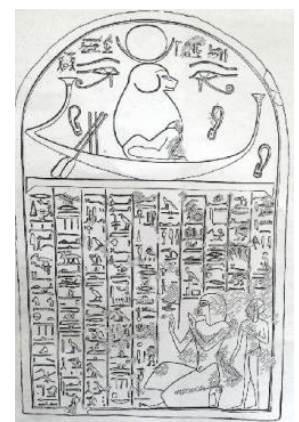

Fig. 10- Stela J. 72025 (after Bruyère, Rapport (1935-40) II, pl. 10, fig 159 no. 111).

The hieroglyphic inscriptions above the baboon's head read: iaH DHwty nTr aAnbHH which is Moon-Thot, Great God, Lord of eternity.

The lower register is separated by the sign of the sky. It is inscribed with ten columns of hieroglyphs. In the lower right corner, Penamun is represented kneeling, and raising his two arms in an adoring position. He is wearing a wig and a long kilt, and behind him stands the naked figure of a

\footnotetext{
'Davies, Who's Who, p. 3.

"PM I: 1, p. 310; Černý, Répertoire, p. 93; KRI III: 730:13, 731:1-4.

"Davies, Who's Who, p. 3, chart 2.

^) PM I, 2, p. 698; Bruyère, Rapport (1935-40) II, p. 42, 79-81, pl. 10-11, fig 159 no. 111; KRI III: 732: 3; Assmann, Ägyptische Hymnen, p. 361 ff; Sadek, Popular Religion, p. 258, Tf. XXI, Abb. 1; Morgan, Untersuchungen zu den Ohrenstelen, p. 86-88.
} 
female child, who is identified by a side lock. She is carrying a bird in her right hand, with her left resting on her heart.

The text reads: rdit iAw n iaH-DHwty aA pHty n psDt sn-tA n pA nTr aA wr n nTrw aA bAw an Htp sDm snmH n iaS n.f ii Hr xrw n dm rn.f sDm nHwt n diw sw m ib.f di.i n.k iAw sqAy(.i) Drt (?) Htp.k nTrw ra nbdi.k anx wDA snb spd [Hr] Hsw mrt qrst nfrt Hr-xt iAw smA tA m smt Hsy Hr imntt wrt nt wAst $\mathrm{n}$ kA n sDm aS m stmAat pn-imn mAa xrw ir n.f $\mathrm{Hr}$ rn n nb.f sA.f mry.f bAkt nt iaH imn-mryt mAa xrw xr nTr aA

Giving praise to Moon-Thot, the Great(est) of Strength of the Ennead. Kissing the ground to the Great God, Great(est) of the Gods, Great of Power; kind and merciful, who hears the prayers of the one who calls to him; who comes at the voice of the one who pronounces his name; who hears the prayers of him who sets him in his heart. I give you praise, (I) raise (my) hand so you are content \{gods?\} every day. May you give life, prosperity, health, alertness, favour and love, a good burial after old age, and funeral in the necropolis of the favoured ones in the mighty West of Thebes, for the ka of the Servant in the Place of Truth, Penamun, true of voice, who has acted for himself in the name of his lord. His daughter, his beloved servant of the Moon, Merytamun, true of voice, before the greatgods.

\section{Stela DM no. 411: ${ }^{91}$}

A round top stela divided into two registers. The upper one represents a solar disc in a barque, with wadjet eye on each side. Traces of unclear hieroglyphic inscriptions can be seen on the top of the stela. The lower register consists of eight columns of hieroglyphs with an adoring figure of Penamun in the lower left corner. He is shown in a squatting position with his two arms raised.

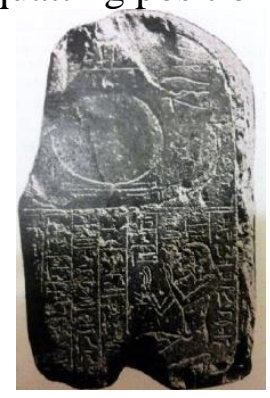

Fig. 11- Stela DM no. 411 (after Bruyère, Rapport (1935-40) II, p.148).

\footnotetext{
"' PM I, 2, p. 731; Bruyère, Rapport (1935-40) II, p. 148, fig 242 no. 411; KRI III: 733:4.
} 


\section{The Tomb of Penamun at Deir El-Madina}

TT213

reads:textthelost,arecolumnssecondandfirstThe

[2 lines lost] [...........................sDm]

[sn]mH n iaS n.f Htp n.i pA an Htp dm.i rn.k iw bw rx pA.k Hr Htp n.i in $\mathrm{sDm}$ aS m

st mAat Pn-imn Dd.f Htp n.i sp 2 wAH kA.k iw.k r Htp

[......who hears the pra]yers of the one who calls to him. Be kind to me, Oh kind and merciful one! I shall pronounce your name, though your face is not known. Be kind to me! By the Servant in the Place of Truth, Penamun. He says: Be kind to me! Twice. As your ka endures, you will be kind.

\section{Stela Cairo J.72020: ${ }^{\top}$}

A round top stela divided into two registers. The upper register represents a hippopotamus, and a papyrus-umbel vase, with no text. The lower register represents two adoring male figures in a squatting position facing each other. Both of them are raising their arms, with two columns of hieroglyphic inscriptions betweenthem.

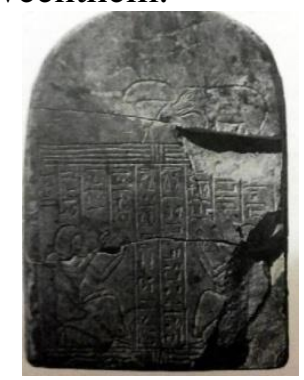

Fig. 12-Stela Cairo J.72020 (after Bruyère, Rapport (1935-40) II, p.101, pl. 16, fig. 173).

In front of the right side figure, the textreads:

rdi(t) iAw n stX aA pHty sA nwt di.f anx wDA snb n kA n [sDmaS m [st] mAat pn-imn [mAa xrw] Giving praise to Seth, the great(est) of strength,son of Nut, he may give life, prosperity, and health to the ka of the [Serv]ant in the [Place] of Truth, Penamun, [true ofvoice].

In front of the left side figure, the text reads:

rdi(T) iAw n st mry ra aA pHty m wiA n HH n kA n sA.f Sdw- imn mAa xrw

\footnotetext{
${ }^{\top}$ PM I, 2, p. 731(b); Bruyère, Rapport (1935-40) II, p. 101, pl. 16, fig. 173, no. 228; KRI III: 733: 5.
} 
Giving praise to Seth, beloved of Re, the great(est) of strength, in the bark of millions, for the ka of his son Shedamen, true of voice.

\section{Ostracon O.CGC 25341}

The text on the ostracon O.CGC $25341^{1 r}$ states:

$[\ldots][\mathrm{sDm}]$ as $\mathrm{n}$ st mAat [....][....] wnn-nfr mAa xrw [sDm aS] $\mathrm{n}$ st mAat xam-wAst [....].f pn-imn mAa xrw [....] pn-imn mAa xrw Give(?), Servant in the place of Truth, $[\ldots . .].[\ldots]$ Wenennefer, True of Voice, [Servant in] the Place of Truth, Khaemwaset, his[son(?)], Penamun, true of voice, [.....] Penamun, true of voice.

The text is best understood from the order of the names as a list of the family of a Wennefer, with son (?) Khaemwaset, and two further [sons?] Penamun. This may represent two, three or four generations of the family.

\section{Stela E 3447 (Louvre Museum): ${ }^{\text {rr }}$}

A round top stela, divided into two registers. The upper register represents a lady sitting on a chair. She is wearing a long tight dress, and a tri-partite wig. Her right hand is on her heart, holding a lotus plant, and her left hand is resting on her knee. In front of her stands a male figure, who is presenting her a lotus flower. The male figure is named as Penamun, represented wearing a long garment, and with a shaved head. Behind him, there is another female figure (a nurse). She is represented with a long dress and tripartite wig, with a cone on her head, and in a squatting position with a child on her knee. She is breast feeding the child, holding her breast by her hand to feed the child. Behind the child, there are representations of a jar and a mirror. ${ }^{r r}$ The top part of the register represents the Shen sign, flanked with two eyes of Horus and seven short columns of hieroglyphs. Above her head, and behind her chair,

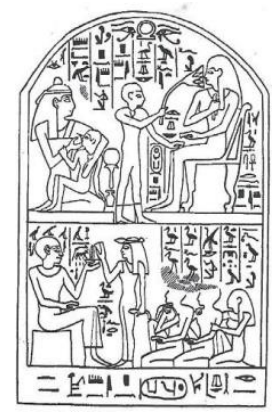

\footnotetext{
${ }^{\top}$ Kitchen mistakenly numbered the Ostraca as O.CGC25342 in KRI III: 733:6.

${ }^{r}$ Bruyère, BIFAO 22, p. 126-127; Bruyère identified this Penamun with the owner of tomb TT213 Deir El Madina despite his dating of this stela to the $18^{\text {th }}$ dynasty.

${ }^{r T}$ Bruyère, BIFAO 22, p. 126.
} 


\section{The Tomb of Penamun at Deir El-Madina}

\section{TT213}

126).p.22,BIFAOBruyère,(afterMuseum--Louvre3447EStela13-Fig.

The text facing left reads:

Mwt-it.f in sA.s sanx rn.s Pn-imn Mut-itef, ${ }^{\xi}$ it is her son who makes her name livePenamun.

Between her and the figure offering, the text, facing right, reads

sA.s Xry-Hb pn-imn Her son, lector priest Penamun.

Above him, the text facing right reads:

Ir.n Xry-Hb(Dsr-kA-ra) Pn-imn

Done by the lector priest of (Djeser-ka-re) Penamun.

Above the nurse, the text, facing right reads

Mnat mwt-rs? The nurse Mut-res?

In front of this a line facing left reads:

(??) pn-inm(??)Penamun

Presumable this indicates she was Penamun's nurse.

The lower register represents a male figure sitting on a stool. He is wearing a long garment, a wide collar, with a shaved head. His right arm is resting upon his knee. His left arm is raised to hold a plate, in which he is receiving a drink from a female figure, standing in front of him. The female figure is wearing a long tight dress with one shoulder strap. She is holding a lotus plant in her right hand. She is also wearing a tripartite wig. Above the seated male figure, the hieroglyphic inscription reads:

$\mathrm{xA} n$ imy-r iHw nfrt-imAw?

Thousand (of offerings) to the Overseer of the Cattle Neferet-imaw?

Above the female figure, text reads:

sAt.sMwt-nfrt

Her daughterMut-nefert.

Behind the female figure, there is a representation of three squatting children in a row; two males and a female. The first male figure is holding a lotus to his chest. The second male is holding the shoulder of his brother by his left arm, while his right is resting on his knee. The female figure is also holding the shoulder and arm of the male in front of her. There are five lines of hieroglyphs above the heads of the squatting figures. The text reads:
sA.fDHwty[....]?
His son Djehwty [...? ]

sA.fbAq?-PA-rs(?)

sAt.snbwt-m-nwt

His son Bak-Pares(?)

Her daughter Nebut-em-nut. ${ }^{\text {or }}$

The lower line of the stela is inscribed with a line a hieroglyphs that reads: ir.n Xry-Hb n Dsr-kA-ra pn-imnmAaxrw Made by the lector priest of (Djeser-ka-re). Penamun, true of voice.

\footnotetext{
¿rMwt it. sis treated as the name of the Lady (the mother of her father).

${ }^{\circ r}$ Ranke, Personennamen, v.II, p. 567.
} 


\section{British Museum stela no. 916. ${ }^{\text {ir }}$}

There is no picture of the stela provided. However, according to Budge, it is a rounded top stela of Penamun(?). Budge identified him as a judge. His name was written as Pn-nxt-imn. This leaves us in doubt whether it belongs to Penamun the owner of tomb TT213 of Deir el Madina or not. Budge described the scene as a deceased in front of queen Ahmose-nefertary, who is wearing the two plumes and a solar disc on her head. A line of hieroglyphic inscriptions reads: HmT nsw(? ${ }^{\vee r}$ wr nb tAwy (iaH-ms-nfrt-iry) mAa xrw. The great wife? of the lord of the two lands. Ahmose-nefertary, true of voice. ${ }^{\lambda r}$

\section{Monuments found in the tomb of Penamun:}



Fig. 14- Fragment of an offering table (after Bruyère, Rapport (1924- 25), p. 188).

- A fragment of an offering table was found inside the tomb of Penamun. The border of the table is inscribed with thetext: ${ }^{9 y}$ [....]Ra-Hr-Axty m[...] [...]Hwt-Hr Hr-tp smt di.sn Ax m pt wsr.s m tA

\footnotetext{
${ }^{7 r}$ Bruyère, Rapport (1924- 25), p. 187, Budge, Guide, p. 100, no. 345; Bruyère mistakenly stated that Penamun was listed on a British Museum basin of libation no. 28, although, there is no mention of his name on the basin. He also identified Penamun with an $18^{\text {th }}$ dynasty Penamun on stela E 3447 of the Louvre Museum (see Bruyère, BIFAO 22, p.126-127).

${ }^{r r}$ Presumably an error for HmT.

${ }^{\lambda r}$ Budge related the stela to the $18^{\text {th }}$ dynasty.

"r Bruyère, Rapport (1924- 25), p. 188.
} 


\section{The Tomb of Penamun at Deir El-Madina} TT213

theiniswhoHathor,in[....],(and)xrw[....]Rehorakhty[....]mAaearth.thein powerandsky, theinakhstategiveshalltheysodesert,voice.oftrue[......]

- A fragment of a white limestone Ushabti was also found in the tomb, it is inscribed with a line oftext: ${ }^{\cdot \Gamma}$ wsir xa-m-wAst mAa xrw. Osiris, Khaemwaset, true of voice.

- Another Ushabti with a line of vertical inscriptions that states: ${ }^{\prime r}$ sHD wsir wnn-[nfr] illuminates, Osiris, Wen[nefer].

\section{Penamun and his affiliations:}

Penamun, the owner of tomb TT213, appears there with the titles: Servant of the Lord of the Two Lands and Servant in the Place of Truth. ${ }^{r}$ His wife is named Nebetnehet. ${ }^{r r}$ His father's name is given there as Baki, with the title Servant in the Place of Truth. ${ }^{\text {¿r }}$ Baki is buried in TT298. ${ }^{\circ r}$ Penamun's mother is Taysen. ${ }^{\text {"T }}$ Baki's parents are Wennefer (Servant in the Place of Truth) and Maya. ${ }^{r r}$ His daughter is Merytamun. His son is Shedamun (or Amenshed).

The only inscription now surviving in the tomb is the damaged entrance doorway. Here the texts of the left side are for "Servant in the Place of Truth Penamun" and his wife "Lady of the House Nebetnehet". The right jamb is for "Servant in the Place of Truth Baki", specifically (in the third column) made "by his son who makes his name live, Penamun". Columns one and two also name, after Baki, "his mother, Lady of the House, Taysen". In principle this could name her as Baki's mother, but it would be normal for Baki's wife to appear here, and so probably she is Penamun'smother.

The fourth column presents the names "[.... Penamun" and "his son Amenmose". The reveal of this jamb presents the names "[. ] Amennakhet" and "his son, Servant in the Place of Truth Penamun". Probably these

\footnotetext{
${ }^{\top}$ Bruyère, Rapport (1924- 25), p.188.

"r Bruyère, Rapport (1924- 25), p.188.

"r PM I: 1, p.310; Černý, Répertoire, p. 93; KRI III: 730:13, 731:1-4, Bruyère, Rapport (1924-25), p.183-188.

${ }^{r r}$ PM I: 1, p.310; Černý, Répertoire, p. 93; KRI III: 730:13, 731:1-4, Bruyère, Rapport (1924-25), p.183-188.

« Černý, Répertoire, p. 93; KRI III: 730:13, 731:1-4, Bruyère, Rapport (1924-25), p. 183 188.

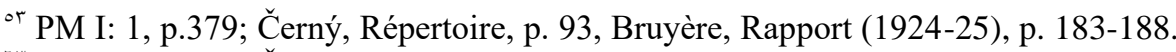

${ }^{\top}$ PM I: 1, p.379; Černý, Répertoire, p. 93, Bruyère, Rapport (1924-25), p. 183-188.

${ }^{r v}$ PM I: 1, p.379; Černý, Répertoire, p. 93.

${ }^{\wedge}$ Černý, Répertoire, p. 93; Davies, Who's Who, p. 3, chart 2.
} 
columns named Baki's sons, so that Amenmose and Amennakhet would be brothers of Penamun, and not his son or father.

Penamun and Nebetnehet are represented as a couple in the tomb of Amenmose. ${ }^{9 r}$ Penamun is also represented with a daughter Merytamun on stela Cairo J. 72025." A lady Nebetnehet, and children Nebansu, and Merytamun are shown on a stela in honour of the Servant in the place of Truth Wennefer.' ${ }^{\text {' }}$ It seems likely that this is the Nebetnehet, wife of Penamun, and Wennefer is her grandfather in law. ${ }^{r \xi}$ Alternatively this might be a different Nebetnehet, who would be a second wife of Wennefer, in addition to Maya, mother of Baki. This is possible; since a son of Wennefer called Nebansu is otherwise known. A Nebansu son of Penamun is not known, but it is a family name and could reasonably be a son whose name does not survive in the very fragmentary part preserved from thetomb. ${ }^{r \varepsilon}$

Davis suggested that Penamun was perhaps not son of Baki, but son of Amennakht and hence a son in law of Baki. He based his argument on reading the entrance door text, as "[........ Amennakht, justified; his son, the servant in the Place of Truth, Penamun, justified'. " However his suggestion is deeply implausible, as he ignored the fact that the text of the left side of the door is dedicated to Baki and his sons, similar to the same sequence of the right side which is dedicated to Penamun and his sons, making it clear that Penamun and Amennakht werebrothers.

According to the sources above, Penamun is the son of Baki, married to Nebetnehet, and the father of Merytamun and Shedamun. The relation between Penamun and Khaemwaset is still obscure. Khaemwaset is likely to be a family member, as his name appeared twice with Penamun. Their appearance together on O.CGC 25341 might indicate that they were brothers. His Ushabti was found in the burial chamber at the bottom of the staircaseshaft, which is not confirmed necessarily to be part of Penamun's tomb. A sensible explanation of the appearance of the names of Khaemwaset and Wennefer in that burial chamber is that it would be a separate part of a family burial complex, but not especially of Penamun.

Penamun is the owner of the chapel, as his name and titles appears on the jambs, but his name was not on the inscriptions of the burial chamber. Bruyère based his suggestion on the appearance of the name of Penamun on the tympanum, which is he read as Pn-imn-nxt, but this is not necessarily correct, nor is it the name of the owner of TT213. Bruyère also identified this

\footnotetext{
${ }^{9 r}$ KRI VII: 41; PM I, 1, p. 18-19(5).

" KRI III: 732: 3; Bruyère, Rapport DM (1935- 40), II, p.42, 79-81.

I؛ Turin Cat. 1543, now N.50051: Tosi \& Roccati, Stele, p. 86, 282; KRI I: 373-374.

rs KRI I, p. 269-270.

r'Davies, Who'sWho,p.3.

¿Davies, Who'sWho,p.3.
} 
Penamun with Pn-nxt-imn, who is represented on the British Museum stela 916; this is also not demonstrated, as it might belong to different Penamun. ${ }^{45}$ The suggested family rlations according to the above source evidence is shown is:

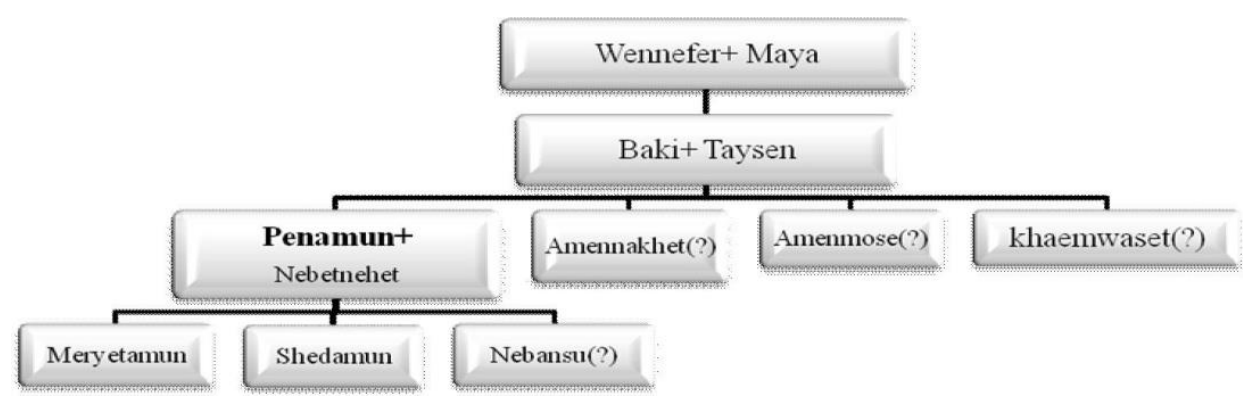

\footnotetext{
${ }^{45}$ Budge identified Pen-nekhet-amun of stela 916 as a judge. He also identified Penamun of the Louvre Museum stela E 3447, who is a lector priest, and dated to the $18^{\text {th }}$ dynasty as identical to the owner of the tomb TT213.
} 


\section{References}

Assmann, J. (1975). Ägyptische Hymnen und Gebete, Zürich, München. Bruyère, B. (1924-1925) Rapport sur les fouilles de Deir el-Medineh, FIFAO, pp. 183-184.

Bruyère, B. (1925). ASAE 25, p. 80-81, pl. 1(2).

Bruyère, B. (1952). Tombes Thébaines de Deir el-Medineh à Décoration Monochrome, MIFAO 86.

Bruyère, B. (1923). "Un Fragment de fresque de Deir el Médineh", BIFAO 22 pp.121-133.

Budge, E.A.W. (1909). A Guide to the Egyptian Galleries(sculpture), London.

Černý, J. (1949). Répertoire Onomastique de Deir El-Mèdineh, Le Caire. Collier, M. (2004). Dating the XIXth Dynasty Ostraca, Leiden.

Davies, B.G. (1999). Who's Who at Deir el-Medina: a prosopographic study of the royal workmen's community, Leiden.

James, T.G.H. (1970). The British Museum Hieroglyphic Texts from Egyptian Stelae etc., part 9, London.

Kampp, F. (1966). Die thebanischen Nekropole: Zum Wandel des Grabgedankens von der XVIII. bis zur XX. Dynastie (Theben, 13), 2 vols.

Kitchen, K.A. (1968-1990). Ramesside Inscriptions: translated and annotated, Oxford: Blackwell.

Lee L. and Quirke S. (2009). Pigments of the Dynastic Period, in Ancient Egyptian Materials and Technology, Cambridge.

Lucas A. (1962). Ancient Egyptian Materials and Industries, London.

Morgan, E. (2004). Untersuchungen zu den Ohrenstelen aus Deir el Medine, Ägypten und Altes Testament 61, Harrassowitz Verlag, Wiesbaden.

Porter, B. and Rosalind M. (1960). Topographical Bibliography of Ancient Egyptian Hieroglyphic Text, Reliefs, and Paintings. I, 1. The Theban Necropolis: Private Tombs. Oxford: Clarendon Press. 
Ranke, H. (1935-1977). Die ägyptischen Personennamen, Augustin, Gluckstadt.

Sadek, A.I. (1987). Popular Religion in Egypt during the New Kingdom, HÄB 27, Gerstenberg.

Tosi, M. \& Roccati, A. (1972). Stele e altre epigrafi di Deir el Medina, n. 50001-n. 50262, E dizioni d'Arte Fratelli Pozzo, Torino. 